\title{
Editorial
}

\section{Getting Research Published}

During the recent ALA annual conference (June 14-20, 2001) in San Francisco, I participated in two different ACRL-sponsored programs focused on "getting published." Both meeting rooms were filled to capacity. There is an apparent strong and widespread interest in learning more about the methods and best practices of writing a research article and getting it published in a reputable journal. Tenure and promotion, of course, are two primary factors driving the desire to get one's research published.

During the Sunday, June 17th, ACRL Research Committee's “Getting Happily Published" program, four journal editors and two authors offered suggestions and insights on authoring, writing articles to fit a particular journal, following instructions for authors, reviewing manuscripts, and including the statement of the problem and appropriate research methodology in the manuscript. After the authors/ editors made their presentations, the audience was given the opportunity to direct questions to the presenters. Based on the questions, it was obvious that some members of the audience knew little about the basics of research and getting its results published. Why is this the case? There are undoubtedly several reasons. One explanation may be that some schools of library and information science do not offer a course on research methods. An academic librarian unequipped with a basic knowledge of research methods is at a tremendous disadvantage when engaged in conducting research, writing up its results, or assisting users who are engaged in research. The ability to comprehend research projects, surveys, and reports should be an important element in the academic librarian's repertoire. If practicing librarians did not have the opportunity to take a research methods class during their MLS program, they should attend meetings such as the two presented at the above-mentioned ALA conference or read a good book on the topic. A good starting point is Ronald R. Powell's Basic Research Methods for Librarians. ${ }^{1}$

\section{Examples of Lack of Understanding}

As a former editor of Library Administration $\mathcal{E}$ Management and Library Hi Tech and the current editor of $C \mathcal{E} R L$, I have had my share of firsthand experience with reading manuscripts received from practicing librarians and library/information science professors. Very few of these manuscripts reflected a thorough knowledge of research methods.

It is not uncommon to receive a manuscript for consideration by $C \mathcal{E} R L$ with some important components missing. For example, an author may submit a manuscript without a "statement of the problem" section. The statement of the problem should be articulated explicitly, not ramble on and on. Research questions have essentially replaced hypotheses. Very few manuscripts received for review by $C \& R L$ contain hypotheses. I receive some manuscripts that do not mention the methodology used in the research process. These types of serious omissions usually result in reviewers not recommending the respective manuscript for publication in $C \mathcal{E} R L$. It is unfortunate that an author spends a huge amount of time gathering data, writing the results of the research, and subsequently having the manuscript rejected due to the omission of some basic components expected to be found in a research manuscript. Some, but not many, 
manuscripts fail to include a literature review. It is apparent that several authors do not read the "Instructions for Authors" found in the January issue of CERL. Manuscripts come to me that far exceed the 5,000-word limitation, are single spaced, do not follow the Chicago Manual of Style (14th edition), and appear to have been written for any other journal except $C \mathcal{E} R L$. Notwithstanding these shortcomings, manuscripts are not normally rejected on the basis of poor stylistic features; content remains paramount.

\section{Suggestions}

Before engaging in a research endeavor, librarians are encouraged to learn as much about basic research methods as quickly as possible. A basic understanding of research methods, coupled with efficiency in their application, is of prime importance. If the opportunity exists, join a mentoring program designed to help librarians learn the fundamentals of research. Consult with a colleague about your research design. Do likewise before you write/publish the results of your re- search. Too many authors, I suspect, simply gallop through the process, send the written report to an editor, and then are shocked to hear that before the manuscript can be published it will require a major rewrite. Beginning the research process thoughtfully and continuing in a deliberate manner will eventually save one much time.

Most of the library research being done involves quantitative methods and the survey, but little qualitative research. Moreover, librarians tend to depend too much on the survey for the research methodology. They have unlimited opportunities to follow different approaches and methodologies in conducting research, and they are encouraged to use them.

The central purpose of this editorial is to assist librarians who may be planning to conduct research and publish its results. Please do not hesitate to contact me if you have any questions about $C \mathcal{E} R L$ (e.g., an idea you have for a proposed manuscript, the suitability of a manuscript for the journal, the review process). If you believe you could use my assistance, please send me an e-message (driggs@nova.edu).

DONALD E. RIGGS

Editor, College $\mathcal{E}$ Research Libraries

\section{Note}

1. Ronald E. Powell, Basic Research for Librarians, 3rd ed. (Greenwich, Conn.: Ablex Publishing, 1997). 